\title{
lodine release from high-burnup fuel structures: Separate-effect tests and simulated fuel pellets for better understanding of iodine behaviour in nuclear fuels
}

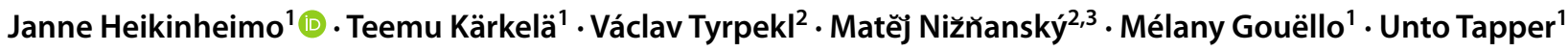

Received: 30 August 2021 / Accepted: 15 November 2021 / Published online: 8 December 2021

(c) The Author(s) 2021

\begin{abstract}
Iodine release modelling of nuclear fuel pellets has major uncertainties that restrict applications in current fuel performance codes. The uncertainties origin from both the chemical behaviour of iodine in the fuel pellet and the release of different chemical species. The structure of nuclear fuel pellet evolves due to neutron and fission product irradiation, thermo-mechanical loads and fission product chemical interactions. This causes extra challenges for the fuel behaviour modelling. After sufficient amount of irradiation, a new type of structure starts forming at the cylindrical pellet outer edge. The porous structure is called high-burnup structure or rim structure. The effects of high-burnup structure on fuel behaviour become more pronounced with increasing burnup. As the phenomena in the nuclear fuel pellet are diverse, experiments with simulated fuel pellets can help in understanding and limiting the problem at hand. As fission gas or iodine release behaviour from high-burnup structure is not fully understood, the current preliminary study focuses on (i) sintering of porous fuel samples with Cs and I, (ii) measurements of released species during the annealing experiments and (iii) interpretation of the iodine release results with the scope of current fission gas release models.
\end{abstract}

\section{Introduction}

High release of iodine has been reported in the annealing experiments of irradiated fuels [1-3]. In the case of hyperstoichiometric $\mathrm{UO}_{2}$, the release of iodine tends to surpass that of xenon [4]. The release of iodine should be reduced if it appears in the fuel in less volatile chemical state, such as CsI. However, earlier studies indicate that the formation of CsI in the fuel should be minor [4]. Despite of the results from international fission product (FP) release experiments at various temperatures [1-3] and mechanistic approaches for fission product transport in irradiated $\mathrm{UO}_{2}$ [5], uncertainties exist for iodine chemical state in the fuel and its release.

Janne Heikinheimo

janne.heikinheimo@vtt.fi

1 Nuclear Energy, VTT Technical Research Centre of Finland Ltd, 02150 Espoo, Finland

2 Department of Inorganic Chemistry, Faculty of Science, Charles University, 12800 Prague, Czech Republic

3 Department of Materials Engineering, Institute of Plasma Physics of the Czech Academy of Sciences, 18200 Prague, Czech Republic
SIMFUEL pellets containing volatile elements require a special approach to retain the volatile material inside the pellet during the sintering procedure. The volatile elements can be implanted in the sintered pellets with ion-implantation techniques [6] or alternative sintering approaches could be used for $\mathrm{UO}_{2}$-CsI mixture $[7,8]$. Typically, a very high temperature is required for $\mathrm{UO}_{2}$ sintering (over $1700{ }^{\circ} \mathrm{C}$ ) but the temperature can be reduced with the spark plasma sintering (SPS) method $[8,9]$. Also, containers with reduced temperature and increased hold time have been successfully tried for the SIMFUEL sintering [7]. In the case of ionimplanted iodine, related iodine diffusion experiments have been conducted with thermal annealing [6].

Non-radioactive $\mathrm{CeO}_{2}$ has been previously applied in fuel pellet-related experiments due to the same crystallographic structure and similar mechanical properties as $\mathrm{UO}_{2}$ [10-13]. In this study, we applied $\mathrm{CeO}_{2}$ powder as surrogate material for $\mathrm{UO}_{2}$ and $\mathrm{PuO}_{2}$. The $\mathrm{CeO}_{2}$ powder was mixed with CsI powder and pressed into pellets with SPS method. Annealing experiments were performed for SPS pellets. 


\section{Experimental details}

\section{Sample preparation}

The $\mathrm{CeO}_{2}$ (Alfa Aesar 5 micron powder, 99.9\%) and CsI (ACROS Organics, 99.999\%) powders were mixed in desired ratio ( $1 \mathrm{~mol} \%$ of $\mathrm{CsI}$ ), blended and ground manually in a mortar. About $1.6 \mathrm{~g}$ of the powder mixture was poured into a graphite punch-die assembly $(8 \mathrm{~mm}$ in diameter) and treated in SPS facility. The annealing was done in a SPS 10-4 10 Ton by Thermal Technology LLC (USA.). Maximum DC heating current is $4000 \mathrm{~A}$ at $10 \mathrm{~V}$ with $40 \mathrm{~kW}$ heating power. Temperature was measured on the die surface using a pyrometer with a measuring range of $600-2200{ }^{\circ} \mathrm{C}$. The final sintering temperatures were set to 900,1000 and $1100^{\circ} \mathrm{C}$ bearing in mind that the allowed maximum sintering temperature is $<1200{ }^{\circ} \mathrm{C}$ due to the boiling point of CsI, which is about $1280{ }^{\circ} \mathrm{C}$. The dwell time at the maximum sintering temperature was 5 minutes, while the applied pressure reached $80 \mathrm{MPa}$.

Final compact dimensions were measured using a micrometre screw KINEX 7031-02-025, and the corresponding geometrical density was calculated (linear approximation between $\mathrm{CeO}_{2}$ and $\mathrm{CsI}$ ). Phase composition of the samples was studied by X-ray powder diffraction (XRD) on a PANalytical X'Pert PRO diffractometer ( $\mathrm{CuK} \alpha$ radiation) and elaborated by Rietveld refinement using FullProf Suite.

The phase composition of the final compacts was confirmed by XRD and Rietveld fit, samples contained $\mathrm{CeO}_{2}$ with fluorite structure (Fm-3m, $a=5.41 \AA$ ) and CsI (Pm$3 \mathrm{~m}, a=4.57 \AA$ ). The higher the sintering temperature, the higher was the observed density of the disc, crossing $81 \%$ of theoretical density at $1100{ }^{\circ} \mathrm{C}$.

\section{Experimental setup for release studies}

The configuration of VTT's fission product transport facility used in the experiments is shown in Fig. 1. The facility has been applied previously, e.g. for the ruthenium transport studies in reactor coolant circuit [14]. The sample was heated to $1500{ }^{\circ} \mathrm{C}$ in an inert argon flow in order to produce vapour species. The total argon flow rate through the facility was $5.0 \mathrm{1} / \mathrm{min}$ (conditions $20^{\circ} \mathrm{C}, 101.325 \mathrm{kPa}$, measured with a Thermal Mass Flowmeter TSI 3063, TSI Incorp.). The pressure inside the facility ranged from 102 to $104 \mathrm{kPa}$. The argon flow directed to the furnace tube was dry. The released species from $\mathrm{CeO}_{2}+\mathrm{CsI}$ sample were transported with gaseous atmosphere to particle analysers, a particle filter and liquid trap for iodine and caesium, respectively. Particle samples were also collected on holey carbon-coated copper (400 mesh) grids with the aspiration sampler. The collected particle samples were analysed with the Transmission Electron Microscopy (TEM). Dry air was applied for dilution of the sample flow for the aerosol analysers. The flow through the iodine trap was $4 \mathrm{l} / \mathrm{min}$.

The liquid trap was filled with a solution of $0.1 \mathrm{M}$ sodium hydroxide $(\mathrm{NaOH})$ and was equipped with the Ion Selective Electrode (ISE) in order to monitor online the concentration of iodide. In addition, during the test, ten samplings (5 $\mathrm{ml}$ ) were performed with a syringe in order to be analysed afterwards by Inductively Coupled Plasma Mass Spectrometry (ICP-MS). The analyses were performed with a Thermo Fisher Scientific HR-ICP-MS Element2 apparatus.

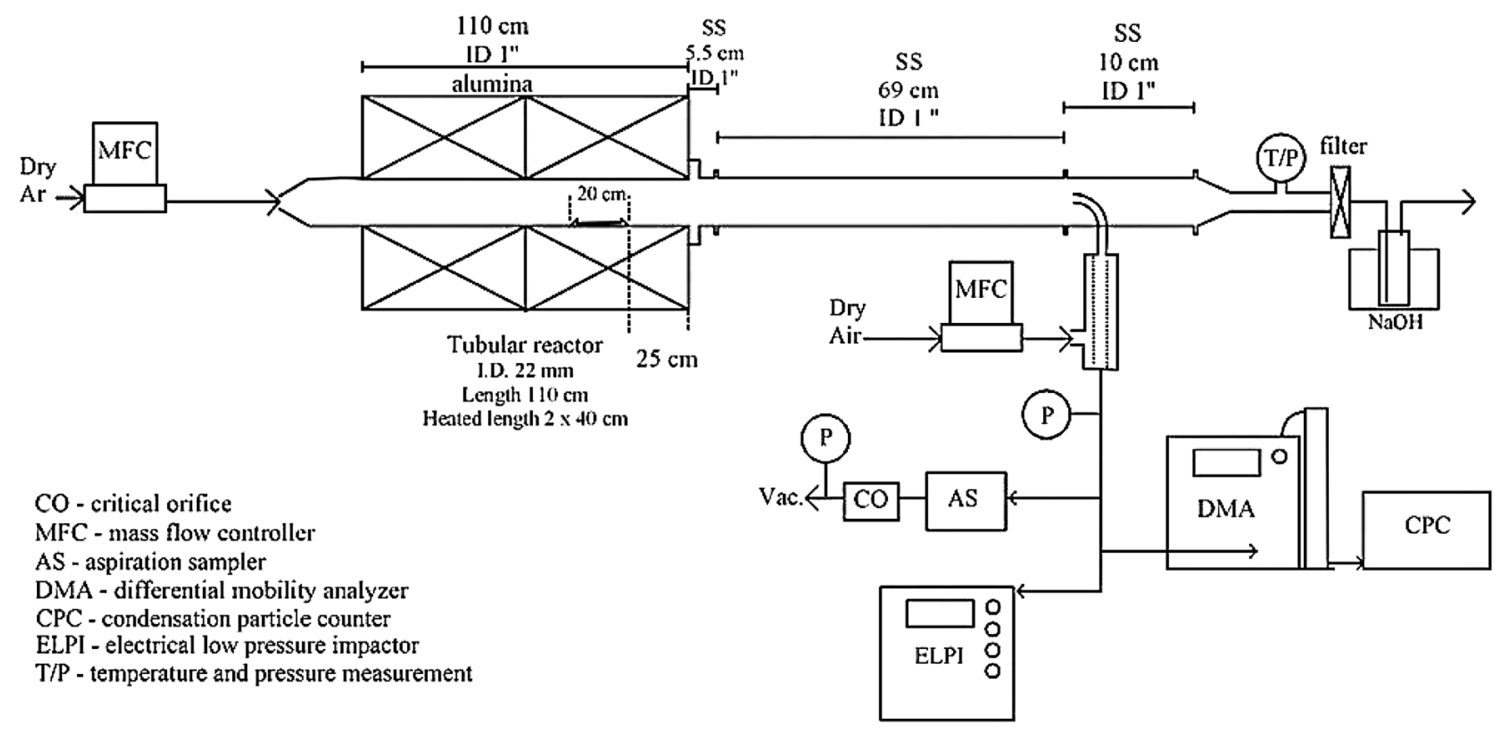

Fig. 1 Schematics of the experimental facility for the $\mathrm{CeO}_{2}+$ CsI release and transport studies 
For the ICP-MS, the iodine and caesium standards and controls, 0.5, 1, 10, 20 and $100 \mathrm{ppb}$, were diluted from the Reference Standard solutions (iodine: Inorganic Ventures CGICI1; caesium: Inorganic Ventures IV-STOCK-21). All measured solutions contained an internal standard; $10 \mu \mathrm{g} / \mathrm{l}$ of rhodium, to control the changes in signal. The samples were injected through PFA $\mu$ flow nebulizer and double-pass spray chamber equipped with Peltier cooling unit. Washing time between the samples was 4 min with pump speed of $11 \mathrm{rpm}$.

The release experiments were started by placing a pellet sample into the reaction furnace and heating up the furnace to the set-point temperature (heating rate of 10 degrees per minute). The gas flow through the facility was started with the heating. When the furnace set-point was reached, the high-temperature (set-point) plateau was maintained for 60 min.

During the heat-up, plateau and cooling-down phases, the reaction products in the form of particles and gas were collected on filters and trapped in a $0.1 \mathrm{M}$ sodium hydroxide solution. At the same time, iodine and particles in the gas phase were analysed with online devices. During the furnace heat-up and plateau phases, particle samples were collected from the gas flow on the TEM grid substrate for the analyses to be conducted later. After the experiment, the gas flows were stopped and the filter was removed. The crucible with the pellet sample was removed from the furnace the next day after the cooling down of furnace to room temperature.

\section{Scanning electron microscopy}

The pellets were analysed prior to the annealing experiments with the Scanning Electron Microscopy (SEM, Zeiss Crossbeam 540 equipped with EDAX Octane Elite ${ }^{\mathrm{TM}} \mathrm{X}$-ray detector) to characterize pellet morphology and CsI distribution in the pellets. The imaging of the $\mathrm{CeO}_{2}$ pellets were conducted using $4 \mathrm{kV}$ electrons while the X-ray analysis was conducted using $15 \mathrm{kV}$ electrons. The probe current was roughly $100 \mathrm{pA}$.

\section{Results}

\section{Characterization of the samples and experimental procedure}

The iodine release experiments were conducted with annealing of the sample pellets, similar to VERDON [2, 3] and HEVA [1] programmes and Turnbull et al.'s studies [15], with the difference that the object of study was a simulated fuel sample instead of irradiated fuel sample. The masses and theoretical densities of the pellets are indicated in Table 1. The table also shows sample outer surface-to-volume ratios. These values were graphically calculated with the Matlab Image Viewer Distance tool for further comparison of the sample release behaviour as the sample pellets were partly cracked in the removal process from spark plasma sintering device.

\section{Structural characterization of the samples}

The studied samples were analysed in SEM to have an overview of the general morphology and degree of pellet porosity. The dispersion of CsI in pellets was studied using elemental analysis with EDS (energy-dispersive $\mathrm{X}$-ray spectroscopy). Cross-section images verified that there are open cavities or pores between crystalline $\mathrm{CeO}_{2}$ particles in all samples. The sintering was more complete with the higher sintering temperature.

Cs or I was not found on the sample cross-section surfaces in the EDS analyses as is indicated in Fig. 2a, b. However, when the $\mathrm{CeO}_{2}$ pellet surface was analysed with SEM, all three samples showed several particles with bright contrast, c.f. Fig. 2c. According to EDS analyses, these particles were rich in caesium and iodine. Thus, it is possible to identify CsI on pellet surfaces based on the secondary electron images and conclude that CsI was typically found as particles at the grain boundaries. Being able to identify CsI by imaging is based on in-lens detector technique in Zeiss Gemini column for imaging secondary electrons (SE) at low electron energies. The in-lens detector is a high-contrast SE detector which is very sensitive, e.g. to charge conductivity of the specimen surface. In this case, it appears that $\mathrm{CeO}_{2}$ has better charge conductivity leading to very bright contrast of CsI particles having poorer electron conductivity. The SPS-900 sample seemed to have more particles on the surface in comparison with SPS-1000 and SPS-1100, respectively.

\section{lodine release and transport from the pellets}

The release from the pellet sample in the crucible was determined by weighing the crucible with the pellet sample before and after each experiment. The difference in mass

Table 1 Experimental matrix of the CsI-doped $\mathrm{CeO}_{2}$ samples containing sample mass and theoretical density

Sample sintering Sample mass Theoretical Sample outer surfacetemperature $\left({ }^{\circ} \mathrm{C}\right) \quad(\mathrm{mg} \pm 1 \mathrm{mg}) \quad$ density $(\%)$ to-volume ratio (1/

$\mathrm{cm})$

\begin{tabular}{llll}
\hline 900 & 1148 & 70 & 15.23 \\
1000 & 1036 & 75 & 16.80 \\
1100 & 1463 & 81 & 24.21 \\
\hline
\end{tabular}

All samples had a similar doping concentration of $1 \mathrm{~mol} \%$. The outer surface-to-volume ratio has been measured for the samples as well 
Fig. 2 SEM/EDS analysis of the cross-sections surfaces of the SPS-900 sample. In $\mathbf{b}$ and $\mathbf{d}$ sum EDS spectrum comprise of integrated X-ray counts per pixels in a and c. The labels in (a) and (c), correspond to spot EDS analyses but are not reproduced here. The peak labels for iodine (I), caesium (Cs) and cerium (Ce) are to indicate their peak locations
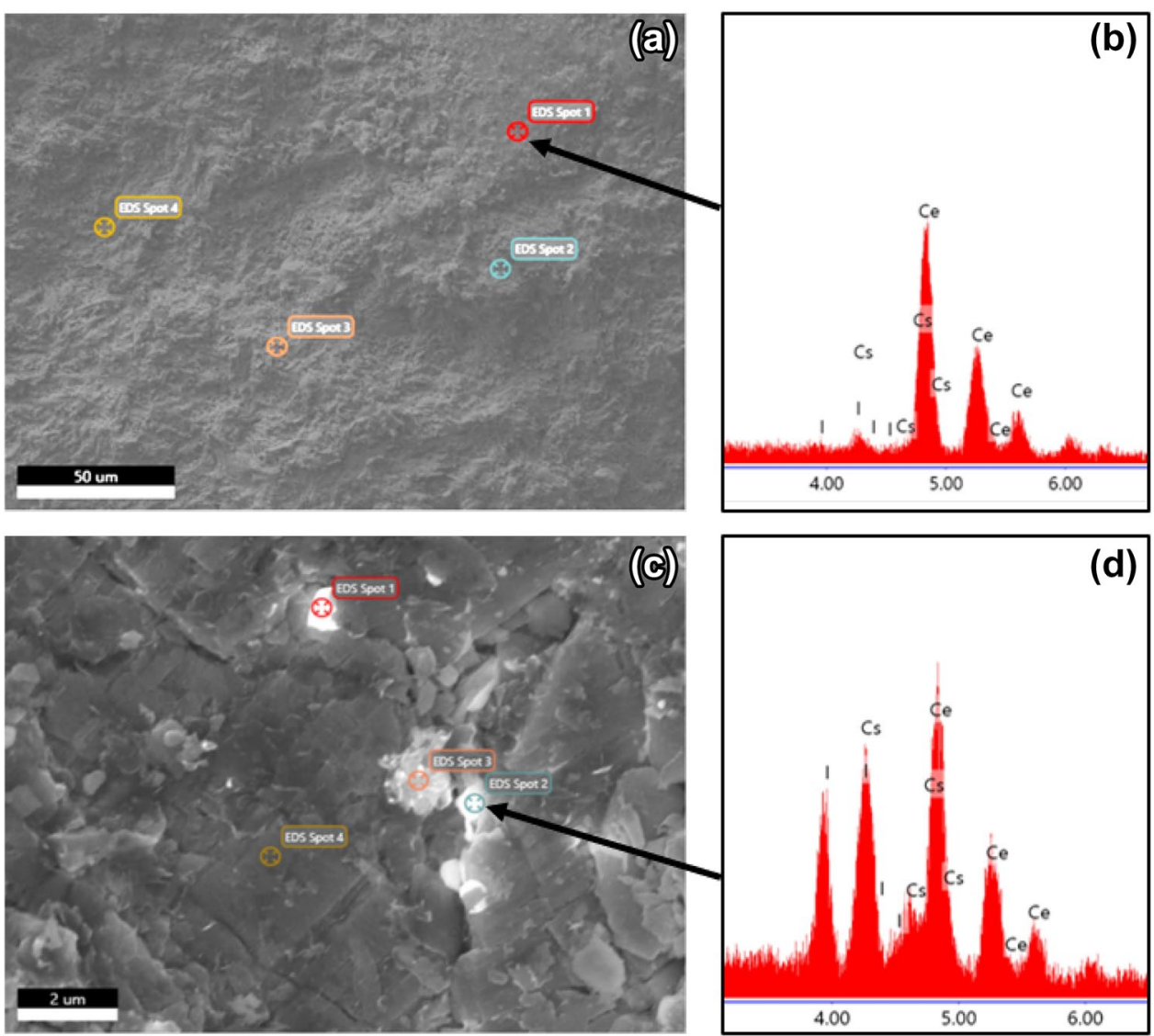

corresponds to the released mass. Similarly, the transported mass to the filter was analysed by weighing the filter before and after each experiment. The obtained results are presented in Table 2. Interestingly, the trend with the pellet weight loss and filter weight gain contradicts with SPS-1000 sample indicating the release of different type or amount of chemical species compared to the other samples. All preannealed samples were grey in colour, typical for non-stoichiometric $\mathrm{CeO}_{2}$ with oxygen vacancies. After the annealing experiments, the colour of all samples had changed to yellow indicating the recovery of oxygen vacancies [16].

The $\mathrm{NaOH}$ trap measurements with ICP-MS show that the release of iodine had already started at $650{ }^{\circ} \mathrm{C}$. Around $1000-1100{ }^{\circ} \mathrm{C}$, the release rate became faster. Then, from 1300 to $1500{ }^{\circ} \mathrm{C}$, the release rate decreased for all the samples.

Figure 3 shows the amount of iodine in the solution samples measured with ICP-MS. To compare the rate of released iodine in relation to the sample microstructure, we normalized the sample masses and macroscopic surface-to-volume ratios by applying values in Table 1 . The difference between the SPS-900 and the other samples is notable. Based on the mass measurements and following the analysis of particles and filters, the iodine release for SPS-900 sample is close to
$100 \%$ at the end of measurements. This has been indicated with an axis for iodine fractional release in Fig. 3.

With the suitable selection of axes for the data in Fig. 3, one can study the diffusional behaviour of the released iodine. We applied an approach based on the Booth model for fission gas release to have insight into iodine diffusional behaviour $[17,18]$. The analysis revealed that the release behaviour of iodine was not purely dominated by diffusion but also other phenomena were present. Possible additional phenomena could be related to iodine chemical interactions and tunnelling effect due to high concentration of iodine at the grain boundaries. Detailed analysis on the iodine diffusional behaviour is presented in the supplementary material.

In addition to the $\mathrm{NaOH}$ solution analysis with the HRICP-MS, the particulate aerosol samples were analysed with TEM and the filters set in front of the $\mathrm{NaOH}$ solution with XRD. The analysis of the aerosol samples revealed that the shape of the particles released from SPS-900 sample were rounder in the shape. The XRD filter analysis revealed that Cs was not released as $\mathrm{CsO}_{2}$ compound from the SPS-900 sample. $\mathrm{CsO}_{2}$ was present in the filters of SPS-1000 and SPS-1100 sample annealing experiments. The amount of Cs trapped in the filters was 9.9e-6, 9.3e-6 and 1.3e-5 mols for SPS-900, SPS-1000 and SPS-1100 samples, respectively. Negligible amount of Cs was found from the liquid trap after 
Table 2 The release from the pellet sample in the crucible and the transported mass to the filter (values corresponding to the flow rate of $41 /$ min through the filter)

\begin{tabular}{lll}
\hline $\begin{array}{l}\text { Sample sintering temper- } \\
\text { ature }\left({ }^{\circ} \mathrm{C}\right)\end{array}$ & $\begin{array}{l}\text { Sample weight loss }(\mathrm{mg} \\
\pm 1 \mathrm{mg})\end{array}$ & $\begin{array}{l}\text { Filter weight } \\
\text { gain }(\mathrm{mg} \pm 0.1 \\
\mathrm{mg})\end{array}$ \\
\hline 900 & 27 & 6.88 \\
1000 & 16 & 8.75 \\
1100 & 18 & 3.75 \\
\hline
\end{tabular}

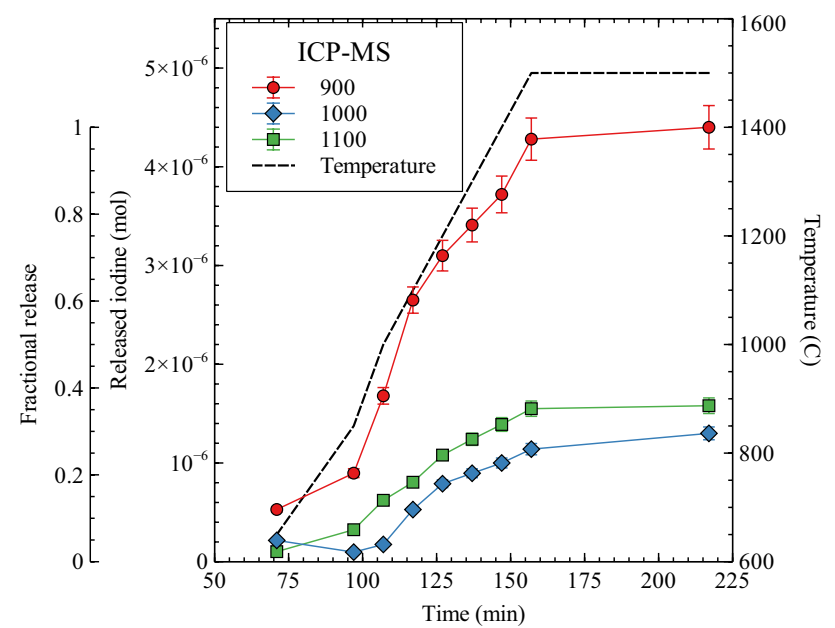

Fig. 3 Released iodine measured with the ICP-MS method with sample outer surface-to-volume ratio and mass normalized against the SPS-900 sample data. The complete fractional release of 1 is set for the SPS-900 series maximum

the filter. Further details are given in the supplementary material.

\section{Conclusions}

Sintering of the $\mathrm{CeO}_{2}$ samples with $1 \mathrm{~mol} \%$ of CsI was done at different temperatures and with similar pressure conditions reaching $80 \mathrm{MPa}$ to create different porous structures and study their implications on caesium and iodine release. The concentrations of caesium and iodine correspond to above $60 \mathrm{MWd} / \mathrm{kgU}$ and $600 \mathrm{MWd} / \mathrm{kgU}$ burnups, respectively [4]. The theoretical densities of the samples annealed with $900{ }^{\circ} \mathrm{C}, 1000{ }^{\circ} \mathrm{C}$ and $1100{ }^{\circ} \mathrm{C}$ were $70 \%, 75 \%$ and $81 \%$, respectively.

The release measurements were performed by annealing samples up to $1500{ }^{\circ} \mathrm{C}$ and measuring the trapped iodine and particles. Iodine was trapped in sodium hydroxide solution and particles were observed with particle analysers. In addition, some particle samples were analysed with TEM and particle filters with XRD. The sample sintered at $900{ }^{\circ} \mathrm{C}$ showed clearly different release behaviour in comparison with the other samples: the amount of released iodine was greater, and the filter analysis did not show caesium oxide as for the rest of the samples. The particle release behaviour, on the other hand, was similar between all samples. TEM analysis indicated that the released particles had more spherical shape for sample with $900{ }^{\circ} \mathrm{C}$ sintering in comparison to the other samples. Further data analysis of iodine release revealed that the behaviour may be dominated by other than simple grain boundary diffusion-related phenomena. Details in particle and further data analysis are documented in supplementary material.

The datasets generated during and/or analysed during the current study are available from the corresponding author on reasonable request.

Supplementary Information The online version contains supplementary material available at https://doi.org/10.1557/s43580-021-00175-1.

Acknowledgments This work was supported by SAFIR2022 Programme (The Finnish Research Programme on Nuclear Power Plant Safety 2019-2022), project INFLAME. This work was also partially supported by the Czech Science Foundation (GAČR), project 20-20936Y "Microstructural and chemical effects during flash sintering of refractory oxides".

Funding Open Access funding provided by Technical Research Centre of Finland (VTT).

Open Access This article is licensed under a Creative Commons Attribution 4.0 International License, which permits use, sharing, adaptation, distribution and reproduction in any medium or format, as long as you give appropriate credit to the original author(s) and the source, provide a link to the Creative Commons licence, and indicate if changes were made. The images or other third party material in this article are included in the article's Creative Commons licence, unless indicated otherwise in a credit line to the material. If material is not included in the article's Creative Commons licence and your intended use is not permitted by statutory regulation or exceeds the permitted use, you will need to obtain permission directly from the copyright holder. To view a copy of this licence, visit http://creativecommons.org/licenses/by/4.0/.

\section{References}

1. J.-P. Leveque, B. Andre, G. Ducros, G.L. Marois, G. Lhiaubet, The HEVA experimental program. Nuclear Technol. 108(1), 33-44 (1994). https://doi.org/10.13182/NT94-A35041

2. Y. Pontillon, S. Bernard, A. Gallais-Durning, B. Gleizes, E. Hanus, G. Ducros, Main outcomes relative to iodine behaviour from the VERDON/ISTP programme, in: International OECD/ NEA-NUGENIA/SARNET Workshop on the Progress in Iodine Behaviour for NPP Accident Analysis and Management, Marseille, France (2020)

3. G. Ducros, Y. Pontillon, P.P. Malgouyres, Synthesis of the VERCORS experimental programme: separate-effect experiments on Fission Product release, in support of the PHEBUS-FP 
programme. Ann. Nuclear Energy 61, 75-87 (2013). https://doi. org/10.1016/j.anucene.2013.02.033

4. H. Kleykamp, The chemical state of the fission products in oxide fuels. J. Nuclear Mater. 131, 221-246 (1985)

5. M.S. Veshchunov, V.D. Ozrin, V.E. Shestak, V.I. Tarasov, R. Dubourg, G. Nicaise, Development of the mechanistic code MFPR for modelling fission-product release from irradiated $\mathrm{UO}_{2}$ fuel. Nuclear Eng. Des. 236(2), 179-200 (2006). https://doi.org/ 10.1016/j.nucengdes.2005.08.006

6. M. Saidy, W.H. Hocking, J.F. Mouris, P. Garcia, G. Carlot, B. Pasquet, Thermal diffusion of iodine in $\mathrm{UO}_{2}$ and $\mathrm{UO}_{2+\mathrm{x}}$. J. Nuclear Mater. 372(2-3), 405-415 (2008). https://doi.org/10.1016/j.jnucm at.2007.03.272

7. J.Z. Liu, S. Miwa, K. Nakajima, M. Osaka, Synthesis of simulated fuels containing CsI under gas-tight condition. Nuclear Mater. Energy 26, 100916 (2021). https://doi.org/10.1016/j.nme.2021. 100916

8. T. Wangle, V. Tyrpekl, M. Cologna, J. Somers, Simulated $\mathrm{UO}_{2}$ fuel containing CsI by spark plasma sintering. J. Nuclear Mater. 466, 150-153 (2015). https://doi.org/10.1016/j.jnucmat.2015.07.030

9. V. Tyrpekl, M. Naji, M. Holzhäuser, D. Freis, D. Prieur, P. Martin, B. Cremer, M. Murray-Farthing, M. Cologna, On the role of the electrical field in spark plasma sintering of $\mathrm{UO}_{2+\mathrm{x}}$. Sci. Rep. 7, 46625 (2017). https://doi.org/10.1038/srep46625

10. C. García-Ostos, J.A. Rodríguez-Ortiz, C. Arévalo, J. Cobos, F.J. Gotor, Y. Torres, Fabrication and characterization of $\mathrm{CeO}_{2}$ pellets for simulation of nuclear fuel. Nuclear Eng. Des. 298, 160-167 (2016). https://doi.org/10.1016/j.nucengdes.2015.12.026

11. C.A. Yablinsky, R. Devanathan, J. Pakarinen, J. Gan, D. Severin, C. Trautmann, T.R. Allen, Characterization of swift heavy ion irradiation damage in ceria. J. Mater. Res. 30(9), 1473-1484 (2015). https://doi.org/10.1557/jmr.2015.43

12. J. Pakarinen, L. He, A.-R. Hassan, Y. Wang, M. Gupta, A. ElAzab, T.R. Allen, Annealing-induced lattice recovery in roomtemperature xenon irradiated $\mathrm{CeO}_{2}: \mathrm{X}$-ray diffraction and electron energy loss spectroscopy experiments. J. Mater. Res. 30(9), 1555-1562 (2015). https://doi.org/10.1557/jmr.2015.13

13. M. Khafizov, J. Pakarinen, L. He, D.H. Hurley, Impact of irradiation induced dislocation loops on thermal conductivity in ceramics. J. Am. Ceram. Soc. 102(12), 7533-7542 (2019). https://doi. org/10.1111/jace. 16616

14. T. Kärkelä, I. Kajan, U. Tapper, A. Auvinen, C. Ekberg, Ruthenium transport in an RCS with airborne CsI. Prog. Nuclear Energy 99, 38-48 (2017). https://doi.org/10.1016/j.pnucene.2017.04.019

15. J. Turnbull, C. Friskney, J. Findlay, F. Johnson, A. Walter, The diffusion coefficients of gaseous and volatile species during the irradiation of uranium dioxide. J. Nuclear Mater. 107(2), 168-184 (1982). https://doi.org/10.1016/0022-3115(82)90419-6

16. K. Ghillanyova, D. Galusek, Chapter 1: Ceramic oxides, in Ceramics Science and Technology, Materials and Properties, ed. By R. Riedel, I.-W. Chen, vol 2. Wiley (2011). ISBN 978-3-527-31156-9

17. A.H. Booth, A method of calculating fission gas diffusion from $\mathrm{UO}_{2}$ fuel and its application to the X-2-f loop test, Technical Report CRDC-721, Atomic Energy of Canada Ltd. (496) (1957)

18. S. Kashibe, $\mathrm{K}$. Une, Effect of additives $\left(\mathrm{Cr}_{2} \mathrm{O}_{3}, \mathrm{Al}_{2} \mathrm{O}_{3}, \mathrm{SiO}_{2}, \mathrm{MgO}\right)$ on diffusional release of ${ }^{133} \mathrm{Xe}$ from $\mathrm{UO}_{2}$ fuels. J. Nuclear Mater. 254, 234-242 (1998) 